\title{
Positive Association of Maternal G Protein $\beta 3$ Subunit 825T Allele with Reduced Head Circumference at Birth
}

\author{
KENTARO MASUDA, HISAO OSADA, YOSHINORI IITSUKA, KATSUYOSHI SEKI, \\ SOUEI SEKIYA \\ Department of Obstetrics and Gynecology, Chiba University Hospital, Chiba University School of \\ Medicine [K.M., H.O., Y.I.] and Department of Reproductive Medicine, Graduate School of Medicine, \\ Chiba University [K.S., S.S.], 1-8-1 Inohana, Chuo-ku, Chiba-shi, Chiba 260-8677 Japan
}

\section{ABSTRACT}

$\mathrm{G}$ protein $\beta 3$ subunit $\mathrm{C} 825 \mathrm{~T}$ polymorphism, which has previously been studied in association with common disorders in adults such as hypertension and obesity, has been focused upon recently for a possible important role in fetal metabolism. Japanese are characterized by having equal allele frequencies for this polymorphism. In this study, we determined the maternal and infantile genotypes in 342 pairs of normal healthy mothers and their infants, and compared the genotype frequencies with various infantile somatoscopic characteristics converted into SD units according to sex, parity and gestational weeks. We observed an association of the maternal (but not infantile) $G$ protein $\beta 3$ subunit $825 \mathrm{~T}$ allele with reduced head circumference but not with reduced birth weight of the neonate. No association was observed between $\mathrm{G}$ protein $\beta 3$ subunit $\mathrm{C} 825 \mathrm{~T}$ polymorphism and various maternal somatoscopic characteristics. Although detailed mechanism of this association requires further research, our results suggest that expression of the $\beta 3$ subunit $825 \mathrm{~T}$ allele in the mother may exert influence on fetal metabolic environment, perhaps through changes in the maternal uterine environment, or on maternal metabolism. (Pediatr Res 52: 687-691, 2002)
BMI, body mass index
SDU, SD units

Numerous hormones, neurotransmitters, chemokines, local mediators, and sensory stimuli exhibit their characteristic effects on the cells through binding with $G$ protein-coupled receptors (1). G proteins bind to these receptors and play the important role of signal transduction for intracellular reactions that are the basis of physiologic responses in tissues and organisms. While mutations of the $\mathrm{G}$ protein gene cause rare diseases such as pseudohypoparathyroidism type I and McCune-Albright syndrome (2), a body of evidence has accumulated which suggests an association between balanced polymorphisms of the $\mathrm{G}$ protein gene and common chronic diseases (3-7).

$\mathrm{G}$ protein is composed of $\alpha, \beta$, and $\gamma$ subunits. Siffert et al. discovered a common polymorphism $(825 \mathrm{C} / \mathrm{T})$ in exon 10 of the gene that encodes the $\beta 3$ subunit (3). The splice variant corresponding to the $825 \mathrm{~T}$ allele synthesizes a protein short of 41 amino acids and one domain. In in vitro studies, this

Received June 26, 2001; accepted April 30, 2002.

Correspondence: Hisao Osada, Department of Obstetrics and Gynecology, Chiba University Hospital, 1-8-1 Inohana, Chuo-ku, Chiba-shi, Chiba 260-8677, Japan; e-mail: osada@med.m.chiba-u.ac.jp

DOI: 10.1203/01.PDR.0000032158.39528.21 truncated protein has been shown to be associated with enhanced activity of $\mathrm{G}$ proteins.

$\mathrm{G}$ protein $\beta 3$ subunit $\mathrm{C} 825 \mathrm{~T}$ polymorphism has attracted attention for its association with common disorders in adults such as hypertension (3-5) and obesity $(6,7)$. It has recently been suggested to play an important role in fetal metabolism (8). In Caucasians, infants of mothers possessing the $825 \mathrm{~T}$ allele had significantly lower birth weights than did infants of mothers homozygous for the 835C allele (9).

Japanese differ from Caucasians in that the frequency of the $825 \mathrm{~T}$ allele is high, and almost equals the frequency of the $825 \mathrm{C}$ allele $(10,11)$. An association between the $825 \mathrm{~T}$ allele and hypertension observed in Caucasians is not found in Japanese $(10,11)$. Thus, it is of interest to examine whether a positive association of maternal $\mathrm{G}$ protein polymorphism with fetal metabolism is replicated in Japanese.

In the present study, we determined the maternal and infantile genotypes in 342 pairs of normal Japanese mothers and their infants, and compared the gene frequencies with various infantile somatoscopic characteristics converted into SD units (SDU) according to sex, parity, and gestational weeks at delivery. We found that the maternal but not infantile $G$ protein 
$\beta 3$ subunit $825 \mathrm{~T}$ allele was associated with reduced head circumference of the neonate.

\section{MATERIALS AND METHODS}

Subjects. Three hundred sixty nonsmoking Japanese women with no remarkable past histories who were followed antenatally at Chiba University Hospital were initially recruited from weeks 12 to 32 of pregnancy. Eighteen women were excluded later because of diseases or circumstances that might independently affect fetal growth. These conditions included preterm delivery (less than $36 \mathrm{wk}$ ' gestation), preeclampsia, pregnancyinduced hypertension, proteinuria, impaired glucose tolerance, preexisting hypertension, fetal anomalies, and placental abnormalities. Each participant in the study gave informed consent under a protocol approved by the local institutional review board.

Phenotypic analysis. The final study group consisted of 342 pairs of mothers and their infants. The following were used as maternal variables: age, parity, gestational week at delivery, method of delivery, systolic and diastolic blood pressures, height, weight before pregnancy, body mass index (BMI) before pregnancy, weight at delivery, and weight gain during pregnancy. For systolic and diastolic pressures, the highest values recorded during the whole course were adopted. The mothers were interviewed at recruitment and asked about their body weights just before pregnancy.

The parameters of fetal growth evaluation were birth weight, length, head circumference, and chest circumference. Birth length was measured by placing the newborn in an extended posture on a measuring board composed of a stationary headboard, a movable footboard, and a built-in tape measure. Head circumference is the greatest dimension of the head joining the inter-superilial space, frontal tuber and occipital tuber. Chest circumference is the greatest dimension of the chest joining bilateral nipples. The actual measurements of birth weight, height, and head circumference were converted into SDU using the mean and SD (SD) values of the standard somatoscopic curves at birth, according to sex and parity (Japanese Ministry of Health and Welfare Research Group 1983, revised in 1994). For instance, birth weight SDU = (birth weight - mean birth weight of infants for the corresponding gestational week, sex and parity $) /(1 \mathrm{SD}$ of infants for the corresponding gestational week, sex and parity).

DNA Preparation and Genotyping. Maternal and infantile genomic DNA was prepared from the peripheral blood of the mother and umbilical cord blood of the infant, respectively, by the phenol-chloroform procedure.

The PCR was performed according to the protocol of Siffert et al. (3) with some modifications. The PCR mixture $(25 \mu \mathrm{L})$ contained $2.5 \mu \mathrm{L}$ of $10 \times$ PCR buffer $(10 \mathrm{mM}$ Tris-HCl, $\mathrm{pH}$ 8.3, $50 \mathrm{mM} \mathrm{KCl}, 2.5 \mathrm{mM} \mathrm{MgCl}$ ), $0.5 \mu \mathrm{L}$ of each dNTP (10 $\mathrm{mM}$ ), $0.2 \mu \mathrm{L}$ of Ampli Taq DNA polymerase (Perkin Elmer Cetus, Emeryville, $\mathrm{CA})(5 \mathrm{U} / \mu \mathrm{L})$, and $1 \mu \mathrm{L}$ of the sense primer (5'-TGACCCACTTGCCACCCGTGC-3') and antisense primer (5'-GCAGCAGCCAGGGCTGGC-3'). DNA was denatured for $4 \mathrm{~min}$ at $94^{\circ} \mathrm{C}$, and then subjected to 30 thermal cycles at $94^{\circ} \mathrm{C}(1 \mathrm{~min}), 65^{\circ} \mathrm{C}(1 \mathrm{~min})$, and $72^{\circ} \mathrm{C}(2 \mathrm{~min})$, followed by a final extension at $72^{\circ} \mathrm{C}(10 \mathrm{~min})$ in a thermal sequencer (Zymoreactor, Atto, Tokyo, Japan).

PCR products were restricted with BseDI (Fermentas, Vilnius, Lithuania), separated on 2.5\% Nusieve GTG agarose gels (FMC BioProducts, Rockland, ME, U.S.A.), stained with ethidium bromide, and visualized under UV illumination. The unrestricted PCR product (TT genotype) has a size of $268 \mathrm{bp}$. Complete restriction (CC genotype) generates bands of $116 \mathrm{bp}$ and $152 \mathrm{bp}$.

Statistical Analysis. All statistical analyses were performed using JMP 4.0 (SAS, Cary, NC, U.S.A.) software. The association between genotypes of $\mathrm{G}$ protein $\beta 3$ subunit $\mathrm{C} 825 \mathrm{~T}$ polymorphism and clinical variables was examined by Student's unpaired $t$ test. The level of significance was set at $p<$ 0.05 .

The sample size was determined from our data of a preliminary study of birth weight measurements in 50 Japanese infants born in our hospital $(3157 \pm 389 \mathrm{~g}$, mean $\pm \mathrm{SD})$. The initial study by Hocher et al. demonstrated a 207-g reduction in birth weight in infants delivered from the mothers with TT/CT genotype. Therefore, a power calculation indicated that approximately 76 subjects per group would be required to have $90 \%$ of power at two-sided $\alpha$ of 0.05 to detect at least a $207-\mathrm{g}$ reduction in body weight. In this study, each genotype for $\mathrm{G}$ protein $\beta 3$ subunit $\mathrm{C} 825 \mathrm{~T}$ polymorphism includes more than 76 subjects.

\section{RESULTS}

G protein $\beta 3$ subunit C825T polymorphism in Japanese subjects. Among the subjects of the present study, the frequencies (\%) of the three genotypes of $\mathrm{G}$ protein $\beta 3$ subunit $\mathrm{C} 825 \mathrm{~T}$ polymorphism were as follows: $\mathrm{TT}: \mathrm{CT}: \mathrm{CC}=25.7: 49.7: 24.6$ in mothers, and TT:CT:CC $=25.7: 44.7: 29.5$ in infants. The frequencies of the $825 \mathrm{~T}$ allele and $825 \mathrm{C}$ allele were almost the same in both mothers and infants. In subsequent analyses, each variable was compared between the TT/CT genotypes that contain the $825 \mathrm{~T}$ allele and the CC genotype that does not contain the $825 \mathrm{~T}$ allele, as well as among each genotype of TT, $\mathrm{CT}$, and $\mathrm{CC}$.

Analysis of maternal genotype and clinical variance. No significant differences were observed between maternal TT/CT and CC genotypes in maternal age $(27.8 \pm 3.9$ versus $28.2 \pm$ 4.0 , mean $\pm \mathrm{SD})$, gestational week at delivery $(39.0 \pm 1.2$ versus $38.6 \pm 2.3 \mathrm{wk}$ ), and systolic and diastolic blood pressures $(115.4 \pm 7.9$ versus $114.1 \pm 7.6$ and $70.5 \pm 8.3$ versus $68.6 \pm 7.9$, respectively). The multipara/nullipara ratio (1.09 versus 1.51$)$, cesarean section ratio ( 7.6 versus $11.7 \%)$ and sex ratio of infants ( 0.93 versus 1.32 , male/female) also were not significantly different between the maternal TT/CT and CC genotypes.

Analysis of maternal genotype and infantile somatoscopic characteristics. The association between maternal genotypes and infantile somatoscopic characteristics at birth is shown in Table 1. The infantile head circumference was $33.3 \pm 1.3 \mathrm{~cm}$ $($ mean $\pm \mathrm{SD})$ in maternal TT/CT genotypes and $33.7 \pm 1.3 \mathrm{~cm}$ in CC genotype, and was significantly smaller in maternal TT/CT genotypes $(p=0.040)$. Even after conversion into 
Table 1. Infantile somatoscopic characteristics and maternal G protein $\beta 3$ subunit C825T polymorphism

\begin{tabular}{lcccc}
\hline \multirow{2}{*}{$\begin{array}{c}\text { Infantile somatoscopic } \\
\text { characteristics }\end{array}$} & \multicolumn{4}{c}{ Maternal genotype } \\
\cline { 2 - 4 } & $\mathrm{TT} / \mathrm{CT}(n=258)$ & $\mathrm{TT}(n=88)$ & $\mathrm{CT}(n=170)$ & $3109(373)$ \\
Birth weight $(\mathrm{g})$ & $3108(258)^{1}$ & $3107(338)$ & $-0.028(0.905)$ & $0.071(0.864)$ \\
Birth weight SDU & $0.002(0.856)$ & $0.053(0.770)$ & $49.3(2.2)$ & $49.2(1.8)$ \\
Length (cm) & $49.3(2.1)$ & $49.3(2.0)$ & $-0.224(1.058)$ & $-0.232(0.903)$ \\
Length SDU & $-0.201(0.076)$ & $-0.160(0.967)$ & $33.4(1.4)$ & $33.7(1.3)^{*}$ \\
Head circumference (cm) & $33.3(1.3)$ & $33.1(1.1)$ & $-0.234(0.891)$ & $-0.008(0.851)^{* *}$ \\
Head circumference SDU & $-0.274(0.783)$ & $-0.344(0.537)$ & $32.3(1.7)$ & $32.7(1.4)$ \\
Chest circumference (cm) & $32.4(1.5)$ & $32.5(1.2)$ & & \\
\hline
\end{tabular}

${ }^{1}$ Values are represented as mean (SD).

${ }^{2} \mathrm{SDU}=$ (birthweight - mean birthweight of infants for the corresponding gestational week, sex and parity)/(1 SD of infants for the corresponding gestational week, sex and parity).

$* p=0.040$ compared with TT/CT mothers, $p=0.011$ compared with TT mothers, $p=0.162$ compared with CT mothers.

** $p=0.028$ compared with TT/CT mothers, $p=0.010$ compared with TT mothers, $p=0.111$ compared with CT mothers.

SDU, a significant difference was observed between the maternal TT/CT and CC genotypes $(p=0.028)$. When our subjects were classified into maternal TT, CT, and CC groups, we obtained a significant difference in head circumference between TT and CC $(p=0.011$ for measured values and 0.010 for SDU) but not between CT and CC.

The mean birth weight was lower in maternal TT/CT genotypes than CC genotype, but the difference was not significant. When expressed in SDU, there also was no significant difference between maternal TT/CT and CC genotypes. No significant differences in length measurement and SDU as well as chest circumference measurement were observed between maternal TT/CT and CC genotypes. Furthermore, we found no significant difference in any of the infantile somatoscopic parameters other than head circumference among maternal TT, $\mathrm{CT}$, and $\mathrm{CC}$ genotypes.

Analysis of infantile genotype and infantile somatoscopic characteristics. The associations between genotypes of infants and infantile somatoscopic characteristics at birth are shown in Table 2. The mean infantile head circumference was $33.3 \mathrm{~cm}$ in infantile TT/CT genotypes and $33.5 \mathrm{~cm}$ in CC genotype, with no significant difference. The mean SDU values were 0.227 and 0.150 for TT/CT and CC genotypes, respectively, and they were not significantly different. Similarly, no significant differences were observed between infantile TT/CT and $\mathrm{CC}$ genotypes in birth weight, length and chest circumference.
Furthermore, we observed no significant difference in any of the infantile somatoscopic parameters among infantile TT, CT, and $\mathrm{CC}$ genotypes.

Analysis of maternal genotype and maternal somatoscopic characteristics. The associations between maternal genotypes and maternal somatoscopic characteristics are shown in Table 3. No significant differences between maternal TT/CT and CC genotypes were observed with respect to maternal height, weight before pregnancy, and BMI before pregnancy. The weight at delivery and weight gain during pregnancy also were not significantly different between maternal TT/CT and CC genotypes. Furthermore, we found no significant difference in any of the maternal somatoscopic parameters among maternal $\mathrm{TT}, \mathrm{CT}$, and $\mathrm{CC}$ genotypes.

\section{DISCUSSION}

Our study demonstrated an association of the maternal $\mathrm{G}$ protein $\beta 3$ subunit $825 \mathrm{~T}$ allele, but not the infantile allele, with reduced head circumference in infants born to women without other risks for reduced fetal growth. Hocher et al. reported a relationship between maternal $825 \mathrm{~T}$ allele and reduced birth weight (9). These findings suggest that expression of the $825 \mathrm{~T}$ allele may exert influences on fetal metabolic environment, perhaps through changes in the maternal uterine environment, or on maternal metabolism.

Table 2. Infantile somatoscopic characteristics and infantile G protein $\beta 3$ subunit C825T polymorphism

\begin{tabular}{|c|c|c|c|c|}
\hline $\begin{array}{c}\text { Infantile somatoscopic } \\
\text { characteristics }\end{array}$ & \multicolumn{4}{|c|}{ Infantile genotype } \\
\hline Birth weight (g) & $3123(364)^{1}$ & $3073(365)$ & $3152(362)$ & $3103(339)$ \\
\hline Length $(\mathrm{cm})$ & $29.4(2.0)$ & $49.4(2.1)$ & $49.5(2.0)$ & $49.0(2.1)$ \\
\hline Length SDU & $-0.151(0.077)$ & $-0.167(0.994)$ & $-0.142(0.966)$ & $-0.351(1.028)$ \\
\hline Head circumference $(\mathrm{cm})$ & $33.3(1.2)$ & $33.2(1.3)$ & $33.4(1.2)$ & $33.5(1.4)$ \\
\hline
\end{tabular}

\footnotetext{
${ }^{1}$ Values are represented as mean (SD).

${ }^{2} \mathrm{SDU}=$ (birthweight - mean birthweight of infants for the corresponding gestational week, sex and parity)/(1 SD of infants for the corresponding gestational week, sex and parity).

No significant differences were observed.
} 
Table 3. Maternal somatoscopic characteristics and maternal G protein $\beta 3$ subunit C825T polymorphism

\begin{tabular}{|c|c|c|c|c|}
\hline $\begin{array}{l}\text { Maternal somatoscopic } \\
\text { characteristics }\end{array}$ & \multicolumn{4}{|c|}{ Maternal genotype } \\
\hline Height $(\mathrm{cm})$ & $157.3(5.2)^{1}$ & $157.8(5.1)$ & $157.0(5.2)$ & $157.0(4.8)$ \\
\hline BMI before pregnancy & $21.4(3.1)$ & $20.9(3.1)$ & $21.6(3.1)$ & $21.6(3.5)$ \\
\hline Weight at delivery $(\mathrm{g})$ & $63.5(8.3)$ & $62.7(8.4)$ & $63.9(8.2)$ & $63.4(8.2)$ \\
\hline Weight gain during pregnancy $(\mathrm{g})$ & $10.5(4.0)$ & $10.5(3.4)$ & $10.5(4.4)$ & $9.5(3.2)$ \\
\hline
\end{tabular}

${ }^{1}$ Values are represented as mean (SD).

No significant differences were observed.

There were basically four outcomes in the offspring; weight, head circumference, length, and chest circumference. Since four multiple comparisons were performed, the $p$ value should be reduced to $0.05 / 4=0.0125$ according to Bonferroni's test, to indicate a statistically significant difference. The $p$ values obtained by comparing the measured head circumferences and their SDU between TT/CT and CC genotypes were above 0.0125 . However, when our subjects were classified into TT, $\mathrm{CT}$, and $\mathrm{CC}$ groups, a significant difference in head circumference was observed between the two maternal homozygous genotypes; TT versus CC ( $p=0.011$ and 0.010 for measured values and SDU, respectively). These $p$ values were below the Bonferroni's corrected $p$ value. On the other hand, no significant difference in infantile head circumference was observed between the maternal heterozygous CT genotype and the CC genotype. In in vitro study, similar increase in G-protein activity was demonstrated in the TT and CT genotypes compared with the CC genotype (3). In contrast, a homozygous state for the maternal $825 \mathrm{~T}$ allele might be necessary for the expression of reduced infantile head circumference.

Signal transduction via pertussis toxin-sensitive $G$ proteins has been shown to be amplified in cells obtained from patients with essential hypertension (12), and splice variant arising from $\beta 3$ subunit $\mathrm{C} 825 \mathrm{~T}$ polymorphism has been implicated in this phenomenon. Therefore, hemodynamic changes in systemic or uteroplacental circulations, or both, may be an intervening step between maternal $825 \mathrm{~T}$ allele expression and fetal growth and development. Similar to the response mediated by $\alpha_{2}$-adrenergic receptor (1), expression of the variant allele may amplify the vasoconstriction effect through $G$ proteindependent pathway and lowers the placental perfusion. Alternatively, adipogenesis may play an intervening role, because augmented signaling by pertussis-toxin-sensitive G-proteins has been proved to stimulate adipogenesis (13).

In our study, maternal $825 \mathrm{~T}$ allele was not associated with any of the somatoscopic variables of the mother. In a study of males aged from 10 to 30 years, subjects possessing the $825 \mathrm{~T}$ allele were more likely to be overweight (BMI $>25 \mathrm{~kg} / \mathrm{m}^{2}$ ) than subjects having the $\mathrm{CC}$ allele, irrespective of ethnicity (7). In our subjects, however, there was no significant difference in $\mathrm{TT} / \mathrm{CT}$ and $\mathrm{CC}$ frequency in overweight subjects (data not shown), suggesting that the $825 \mathrm{~T}$ allele is not associated with obesity in Japanese women in the 20- to 40-year age group. Our results also suggest that although expression of the 825T allele indirectly affects development during the fetal stage via maternal influence, the effect of this gene expression may not be operative after birth.
Additionally, we found no difference between the TT/CT and $\mathrm{CC}$ genotypes in maternal systolic and diastolic blood pressures, although the data were one-point measurements. Previous studies also reported no association between C825T polymorphism and hypertension in Japanese $(10,11)$. Even if the effect of the $825 \mathrm{~T}$ allele on fetal growth is mediated by vasoconstriction, this effect may not affect the systemic blood pressure of Japanese women in the 20- to 40-year age group. The interaction among phenotypes developed as a result of in utero effect conferred by the maternal $825 \mathrm{~T}$ allele, and the phenotypes developed from expression of the $825 \mathrm{~T}$ allele by the individual him/herself needs to be elucidated.

We observed an association of maternal $G$ protein $\beta 3$ subunit $825 \mathrm{~T}$ allele with reduced head circumference of infants, whereas Hocher et al. found an association between the 825T allele and reduced birth weight (9). Although they also found a similar reduction in head circumference in absolute terms $(0.7 \mathrm{~cm})$, the difference was not statistically significant One reason for this discrepancy may be the difference in handling of somatoscopic characteristics. Hocher et al. analyzed the somatoscopic measurements as absolute values (9), whereas we analyzed both absolute values and values converted to SD units based on the mean and SD of Japanese fetal growth curves according to sex and parity. SDU is adjusted for the variations arising from differences in sex, parity, and gestational week, and provides more accurate analysis. Our analyses using absolute values and SD units both showed a significant difference between maternal TT/CT and CC genotypes in head circumference but not birth weight of the infant.

Another reason for the inconsistent findings by us and Hocher et al. is the difference in allele frequency of G protein $\beta 3$ subunit $\mathrm{C} 825 \mathrm{~T}$ polymorphism. We showed almost the same frequency of $825 \mathrm{~T}$ and $825 \mathrm{C}$ alleles, in agreement with previous reports on Japanese $(10,11)$. The report of Hocher et al. showed a ratio of approximately 1:2 for the two alleles (9). If the homozygote shows a stronger association than the heterozygote, then the analysis of Hocher et al. may not yield a significant difference because the frequency of TT genotype in their subjects was low. As described above, when we classified our subjects into maternal TT, CT and CC groups, we obtained a significant difference in head circumference between maternal TT and CC but not between CT and CC.

The reduction in head circumference we found in this study was of a small degree (a difference of $0.4 \mathrm{~cm}$ between TT/CT and (C), and therefore should not have an immediate clinical importance. Nevertheless, the head circumference at birth not only denotes a parameter of the somatoscopic characteristics, 
but may have greater significance as an independent indicator of the outcome of cranial or neurologic development in the fetal stage. The head circumference at birth has been reported to be proportional to the neonatal brain volume measured by computed tomography (14). Smoking during pregnancy has been reported to reduce the neonatal head circumference (15), and a concern of the possible effect on future neurologic development has been raised. Similarly, the reduction in head circumference associated with the maternal $825 \mathrm{~T}$ allele shown in this study may affect long term neurobehavioral outcome.

\section{CONCLUSIONS}

In conclusion, the $\mathrm{G}$ protein $\beta 3$ subunit $\mathrm{C} 825 \mathrm{~T}$ allele in healthy normal Japanese pregnant women was associated with a reduced head circumference in their infants. Our study lends support to the effect of genetic variation of $\mathrm{G}$ protein on fetal growth and development via expression in the maternal body.

\section{REFERENCES}

1. Hamm HE 1998 The many faces of G protein signaling. J Biol Chem 273:669-672

2. Farfel Z, Bourne HR, Iiri T 1999 The expanding spectrum of G protein diseases. N Engl J Med 340:1012-1020

3. Siffert W, Rosskopf D, Siffert G, Busch S, Moritz A, Erbel R, Sharma AM, Ritz E, Wichmann HE, Jakobs KH, Horsthemke B 1998 Association of a human G-protein beta3 subunit variant with hypertension. Nat Genet 18:45-48

4. Feldman RD, Hegele RA 2000 G-protein polymorphisms and maternal/neonatal metabolism: still a weight for the answer 202 Lancet 355:1201-1201
5. Beige J, Hohenbleicher H, Distler A, Sharma AM 1999 G-Protein beta3 subunit C825T variant and ambulatory blood pressure in essential hypertension. Hypertension 33:1049-1051

6. Dong Y, Zhu H, Sagnella GA, Carter ND, Cook DG, Cappuccio FP 1999 Association between the $\mathrm{C} 825 \mathrm{~T}$ polymorphism of the $\mathrm{G}$ protein beta3-subunit gene and hypertension in blacks. Hypertension 34:1193-1196

7. Hegele RA, Anderson C, Young TK, Connelly PW 1999 G-protein beta3 subunit gene splice variant and body fat distribution in Nunavut Inuit. Genome Res 9:972977

8. Siffert W, Forster P, Jockel KH, Mvere DA, Brinkmann B, Naber C, Crookes R, Du P, Heyns A, Epplen JT, Fridey J, Freedman BI, Muller N, Stolke D, Sharma AM, Al Moutaery K, Grosse-Wilde H, Buerbaum B, Ehrlich T, Ahmad HR, Horsthemke B, Du Toit ED, Tiilikainen A, Ge J, Wang Y, Yang D, Husing J, Rosskopf D 1999 Worldwide ethnic distribution of the $\mathrm{G}$ protein beta3 subunit $825 \mathrm{~T}$ allele and its association with obesity in Caucasian, Chinese, and Black African individuals. J Am Soc Nephrol 10:1921-1930

9. Hocher B, Slowinski T, Stolze T, Pleschka A, Neumayer HH, Halle H 2000 Association of maternal $\mathrm{G}$ protein beta3 subunit $825 \mathrm{~T}$ allele with low birth weight. Lancet 355:1241-1242

10. Kato N, Sugiyama T, Morita H, Kurihara H, Yamori Y, Yazaki Y 1998 G protein beta3 subunit variant and essential hypertension in Japanese. Hypertension 32:935938

11. Ishikawa K, Imai Y, Katsuya T, Ohkubo T, Tsuji I, Nagai K, Takami S, Nakata Y, Satoh H, Hisamichi S, Higaki J, Ogihara T 2000 Human G-protein beta3 subunit variant is associated with serum potassium and total cholesterol levels but not with blood pressure Am J Hypertens 13:140-145

12. Siffert W, Rosskopf D, Moritz A, Wieland T, Kaldenberg-Stasch S, Kettler N, Hartung K, Beckmann S, Jakobs KH 1995 Enhanced G protein activation in immortalized lymphoblasts from patients with essential hypertension. J Clin Invest 96:759766

13. Moxham CM, Hod Y, Malbon CC 1993 Induction of G alpha i2-specific antisense RNA in vivo inhibits neonatal growth. Science 260:991-995

14. Lindley AA, Benson JE, Grimes C, Cole Tr, Herman AA 1999 The relationship in neonates between clinically measured head circumference and brain volume estimated from head CT-scans. Early Hum Dev 56:17-29

15. Kallen K 2000 Maternal smoking during pregnancy and infant head circumference at birth. Early Hum Dev 58:197-204 